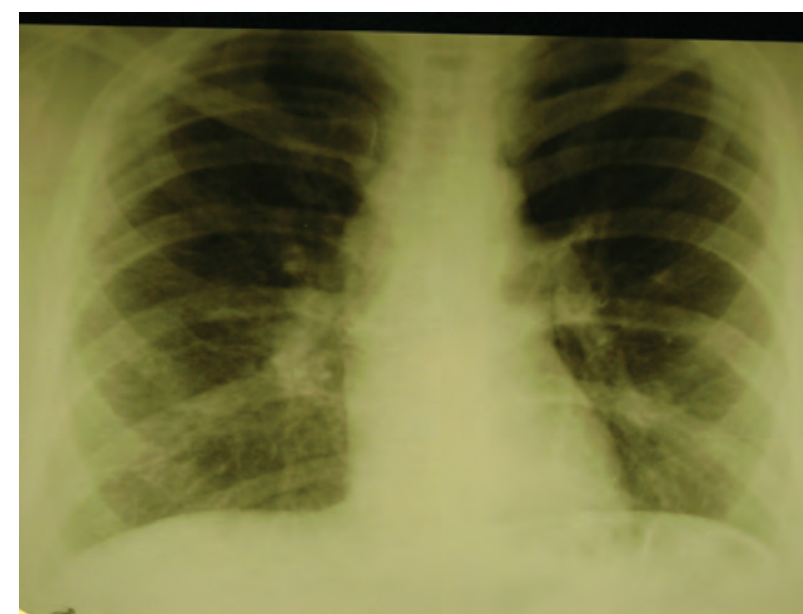

Рис. 2. Обзорная рентгенограмма легких больной И. после курса экстракорпоральных методов лечения и лечебного голодания гемограммы, отмечался прирост по данным ФВД. У пациентки значительно уменьшилась одышка, нормализовалась температура, исчезло ощущение дискомфорта за грудиной.

Заключение. Данным примером мы показали возможность применения альтернативных методов лечения у пациентов с впервые выявленным саркоидозом, сопутствующими заболеваниями и невозможностью применения адекватных доз системных ГКС

\section{ЛИТЕРАТУРА}

1. Sarcoidosis // Eur. Radiol. - 2005. - Vol. 15. - P. 23-30.

2. Kreit, J.W. Hemoptysis / J.W. Kreit // Clinical Respiratory Medicine. - 2004. - Mosbiy. - P. 249-255.

3. Lachkar, S. Aspergillosis and sarcoidosis / S. Lachkar, S. Dominique, L. Thiberville [et al.] // Rev. Mal. Respir. 2007. — Vol. 24, № 8. - P. 943-953.

4. Schreiber, J. Differential diagnosis of diffuse pulmonary haemorrhage / J. Schreiber, J. Knolle, R. Kachel, R. Schuck // Pneumologie. - 2006. - Vol. 60, № 6. - P. 347-354.

\title{
АНТИГЕНИНДУЦИРОВАННЫЙ ИНТЕРФЕРОН ГАММА ПРИ САРКОИДОЗЕ, ТУБЕРКУЛЕЗЕ И НЕСПЕЦИФИЧЕСКИХ ВОСПАЛИТЕЛЬНЫХ ЗАБОЛЕВАНИЯХ ЛЕГКИХ
}

НАТАЛЬЯ ВЛАДИМИРОВНА МАКАРОВА, канД. мед. Наук, врач-пульмонолог Клиники фтизиопульмонологии Московского медицинского университета им. И.М. Сеченова Росздрава, Москва (8-495-688-27-78, e-mail: nmyke@mail.ru) СЕРГЕЙ ЕВГЕНЬЕВИЧ БОРИСОВ, докт. меД. наук, профессор, заместитель директора по научно-клинической работе Московского городского научно-практического центра борьбы с туберкулезом Департамента здравоохранения города Москвы (8-499-268-50-10, e-mail: barsik@online.ru)

МИХАИЛ АЛЕКСАНДРОВИЧ ВЛАДИМИРСКИЙ, докТ. мед. наук, профессор, заведующий лабораторным отделом НИИ фтизиопульмонологии Московского медицинского университета им. И.М. Сеченова Росздрава, Москва (8-917-541-62-38)

ТАТЬЯНА НИКОЛАЕВНА ВЛАСИК, канд. биол. наук, руководитель лаборатории клеточной инженерии Российского кардиологического научно-производственного комплекса Росмедтехнологий, Москва (8-495-414-69-54)

Реферат. Исследована концентрация ИФН-ү в образцах крови, полученных от 67 больных саркоидозом, 60 туберкулезом и 44 - неспецифическими воспалительными заболеваниями легких. Средние значения концентрации (пг/мл) ИФН-ү после 24 ч инкубирования с PРD при туберкулезе $(302,1 \pm 32,6 ; 95 \%$ ДИ 236,9-367,4) были достоверно выше, чем при саркоидозе $(66,7 \pm 16,8 ; 95 \%$ ДИ 33,2-100,2). При воздействии ESAT-6 показатели при саркоидозе были минимальны $(9,2 \pm 2,98 ; 95 \%$ ДИ 3,3-15,2), достоверно отличаясь от таковых при туберкулезе

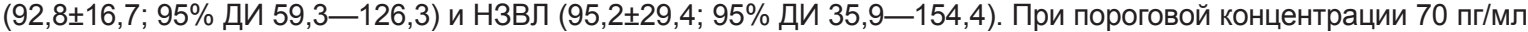
(как при использовании в качестве антигена-индуктора PPD, так и ESAT-6) диагностическая эффективность теста для различения саркоидоза и туберкулеза составила 77,9\%, чувствительность - 76,1\%, специфичность 80\%. При концентрации ИФН-ү менее 70 пг/мл шансы на наличие у больного саркоидоза выше, чем на наличие туберкулеза в 12,8 раза (95\% ДИ 5,1-32,8).

Ключевые слова: саркоидоз, туберкулез, неспецифические воспалительные заболевания легких, гаммаинтерферон.

\section{ANTIGEN-INDUCED INTERFERON- $\gamma$ IN SARCOIDOSIS, TUBERCULOSIS AND NON-SPECIFIC INFLAMMATORY LUNG DISEASES}

\author{
N.V. MAKAROVA, S.E. BORISOV, M.A. VLADIMIRSKIY, T.N. VLASIK
}

\begin{abstract}
The serum concentration of IFN-y after 24-hours incubation with PPD/ESAT-6 was estimated in patients with sarcoidosis (67), tuberculosis (60) and non-specific lung inflammation (44). The mean concentration (picogram/ $\mathrm{ml}$ ) after PPD-incubation was significantly higher in tuberculosis $(302,1 \pm 32,6 ; 95 \% \mathrm{Cl} 236,9-367,4)$ in comparison with sarcoidosis $(66,7 \pm 16,8 ; 95 \% \mathrm{CI} 33,2-100,2)$. After ESAT-6-incubation IFN- $y$ concentration in sarcoidosis was the lowest $(9,2 \pm 2,98 ; 95 \% \mathrm{Cl} 3,3-15,2)$, in comparison with tuberculosis $(92,8 \pm 16,7 ; 95 \% \mathrm{Cl} 59,3-126,3)$ and non-specific lung inflammation $(95,2 \pm 29,4 ; 95 \% \mathrm{Cl} 35,9-154,4)$. The IFN-y concentration level 70 picogram $/ \mathrm{ml}$ (both PPD- and ESAT-6induced) provides the diagnostic accuracy for sarcoidosis and tuberculosis differentiation $77,9 \%$, sensitivity $-76,1 \%$, specificity $-80 \%$. Odds ratio for sarcoidosis in patients with IFN-y concentration level less then 70 picogram $/ \mathrm{ml}$ is $12,8(95 \% \mathrm{Cl} 5,1-32,8)$.

Key words: sarcoidosis, tuberculosis, non-specific inflammatory lung diseases, $\mathrm{y}$-interferon.
\end{abstract}


B ведение. Задача дифференциальной диагностики саркоидоза и туберкулеза достаточна сложна, причем в ряде случаев однозначное заключение о нозологической природе процесса не может дать и гистологическое исследование биоптатов ткани легкого и лимфатических узлов [2, 3]. Сходные жалобы, клинические и рентгенологические проявления затрудняют своевременное распознавание туберкулеза (особенно без бактериовыделения) и неспецифических пневмоний [1].

Новые возможности для дифференциальной диагностики туберкулеза и сходных с ним заболеваний органов дыхания открывает выделение высокоспецифичных антигенов M.tuberculosis, в том числе ESAT-6, и создание тест-систем, основанных на определении индуцированного ИНФ-ү в сыворотке крови in vitro в ответ на стимуляцию антигенами, присутствующими только у M.tuberculosis complex [4, 5, 6, 9]. Предполагается, что применение высокоспецифичных антигенов обеспечит исключение ложноположительных и ложноотрицательных результатов, возможных при перекрестных (антиген-антитело) реакциях в кожных туберкулиновых тестах [8]. При этом по-разному оцениваются ситуации выявления латентной туберкулезной инфекции и активного туберкулеза [7, 8], особенно в регионах с высокой распространенностью туберкулезной инфекции.

Цель исследования - оценить возможность использования определения концентрации антигениндуцированного ИНФ-ү под воздействием туберкулина (PPD) и ESAT-6 в целях дифференциальной диагностики саркоидоза, туберкулеза и неспецифических воспалительных заболеваний легких среди жителей Российской Федерации, для которой характерно широкое распространение туберкулезной инфекции и относительно высокая заболеваемость туберкулезом.

Материал и методы. Проведено сопоставление клинических и иммунологических проявлений заболеваний легких различного генеза у 171 больного, находившегося в клинике фтизиопульмонологии ММА им. И.М. Сеченова в 2005-2008 гг. Специальный отбор больных не проводили, зачисление в группы осуществляли «сплошным» методом по мере госпитализации больных.

Среди больных преобладали мужчины (93 человека - 54,7\%) и лица моложе 40 лет (99 человек $57,9 \%)$. Практически все пациенты были госпитализированы впервые с целью установления диагноза и определения тактики ведения. Всем больным проведены общепринятые клинические, лабораторные, микробиологические, рентгенологические, функциональные исследования, по показаниям - морфологическая верификация диагноза (трансбронхиальная биопсия легких или прескаленная биопсия лимфоузла).

Первую группу составили 67 больных саркоидозом: у 4 (6\%) человек был диагностирован саркоидоз внутригрудных лимфатических узлов (ВГЛУ), у 48 (72\%) - саркоидоз ВГЛУ и легких, у 15 (22\%) - генерализованный саркоидоз. 60 больных туберкулезом (ТБ) составили вторую группу; из них у 35 (58,3\%) человек имел место инфильтративный ТБ, у 9 (15\%) - диссеминированный, у 11 (18,3\%) - очаговый, у 4 (6,7\%) туберкулемы, а у $1(1,7 \%)$ пациентки диагностирован генерализованный ТБ с поражением легких, почек и маточных труб. В третью группу вошли 44 пациента с неспецифическими воспалительными заболеваниями легких (НВЗЛ); у 11 (25\%) человек диагностирован хронический обструктивный бронхит, у 24 (54,5\%) неспецифическая пневмония, у 3 (6,8\%) - бронхиальная астма инфекционно-аллергического генеза, у $5(11,4 \%)$ - необструктивный бронхит, у 1 (2,3\%) пациента - неспецифический пневмосклероз.

Исследовали венозную кровь, которую немедленно после забора (не менее 3,5-4,0 мл) переносили в стерильную пробирку с 0,05 мл (50 ЕД) гепарина и, покачивая, перемешивали. Гепаринизированную кровь вносили по 1 мл в три лунки 24-луночного планшета, маркированные как К (контроль), PPD и ESAT-6, куда соответственно вносили по 10 мкл антигенов PPD (сухой очищенный туберкулин 50000 ТЕ, СПб НИИ вакцин и сывороток) и ESAT-6. Затем образцы перемешивали при осторожном покачивании. После инкубации при $37^{\circ} \mathrm{C}$ в течение $20-24$ ч из лунок, не перемешивая, извлекали 200-300 мкл плазмы для количественного иммуноферментного анализа (ИФА). Образцы плазмы до постановки ИФА хранили при температуре $-20^{\circ} \mathrm{C}$ сроком до 1 мес. Перед анализом оттаявшие образцы тщательно перемешивали; повторное замораживание и оттаивание образцов не допускалось.

Применяли экспериментальную иммуноферментную тест-систему с использованием двух моноклональных антител. Посадочные моноклональные антитела (5 мкг/мл в карбонат-бикарбонатном буфере $\mathrm{pH}=9,6$ ) инкубировали при температуре $+4^{\circ} \mathrm{C}$ в течение ночи на 96-луночных полистироловых планшетах фирмы Nunc (США), отмывали 4 раза в 0,05\% растворе твин-20; все последующие процедуры отмывки проводили аналогично. Для ИФА использовали два моноклональных антитела к различным детерминантам ИФН-у: иммобилизованные в лунках планшета и детектирующие антитела, меченные биотином. ИФН-ү, связанный с помощью первых антител в лунках планшета, выявляли с помощью вторых биотин-меченых антител и ферментного конъюгата - стрептадивин-пероксидазы. После остановки реакции стоп-реагентом результаты анализировали с помощью микроридера MR-4 (США). Для определения концентрации ИФН-ү строили калибровочную кривую на основании измерения оптической плотности при 450 нм в лунках стандартного ИФН-ү с двукратным разведением от 280 пг/мл до 8,75 пг/мл. Чувствительность анализа -10 пкг/мл. Определяли концентрацию ИФН-ү в образцах крови, инкубированных с антигенами PPD и ESAT-6, за вычетом уровня отрицательного контроля (концентрация ИФН-ү в контрольной пробирке без антигенов).

Статистическую обработку результатов проводили с помощью программы SPSS 11,5. Показатели, подчиняющиеся нормальному распределению, представлены в виде $\mathrm{M} \pm \mathrm{m}$ (среднее значение \pm стандартная ошибка среднего); показатели с распределением, отличающимся от нормального, описывали при помощи медианы и диапазона колебаний или интерквартильного размаха; качественные показатели - в долях (процентах). Определены 95\%-ные доверительные интервалы (ДИ) количественных показателей. Статистический межгрупповой анализ данных, не подчиняющихся нормальному распределению, проводили с помощью критерия Манна-Уитни.

Результаты и их обсуждение. Средние значения концентрации ИФН-ү при индукции PPD были наиболее высокими при ТБ и наименьшими при саркоидозе. Несмотря на то что максимальная концентрация PPDиндуцированного ИФН-ү отмечена у больного с НВЗЛ 
(1172,4 пг/мл), распределение значений с первой по третью квартиль (25-75\% процентили) показало, что у большей части больных ТБ концентрация PPDиндуцированного ИФН-ү почти в 2 раза выше, чем при НВЗЛ и почти в 6,5 раз выше, чем при саркоидозе. При сравнении концентрации индуцированного ИФН-ү, в связи с далеким от нормального распределением независимых выборок, для определения достоверности использован U-тест по Манну-Уитни. Согласно данному тесту, концентрация PPD-индуцированного ИФН-ү статистически достоверно различалась между всеми тремя группами больных (табл. 1).

При индукции более специфическим антигеном ESAT-6 средние показатели концентрации ИФН-ү были существенно ниже, чем при индукции PPD. Более чем у половины больных саркоидозом индукция ИФН-ү на ESAT-6 отсутствовала. При НВ3Л у основной части больных $(75 \%)$ концентрация ESAT-6-индуцированного ИФН-ү не превышала 69 пг/мл. У некоторых больных во всех изучаемых группах выявлены показатели, существенно превышающие средние значения, но взаимосвязи высокой концентрации ESAT-6-индуцированного ИФН-ү и клинико-рентгенологической картины, лабораторных показателей, бактериовыделения не выявлено. Согласно U-тесту по Манну-Уитни, концентрация ESAT-6-индуцированного ИФН-ү достоверно отличалась между больными ТБ и саркоидозом, ТБ и НВЗЛ, а также между саркоидозом и НВЗЛ (табл. 2).

Исследование позволило определить пороговые значения концентрации антигениндуцированного ИФН-ү в сыворотке крови (табл. 3, 4). Оптимальное соотношение чувствительности и специфичности обеспечивается при пороговой концентрации 70 пг/мл, превышение которой свидетельствует в пользу туберкулезной этиологии легочного процесса (как при использовании в качестве антигена-индуктора PPD, так и ESAT-6).

Диагностическая эфффективность принятого критерия в диффреренциальной диагностике саркоидоза и ТБ равна $77,9 \%$, чувствительность - 76,1\%, а специфичность - 80\%. О высокой достоверности результатов свидетельствует критерий $\chi^{2}(p<0,001)$. При концентрации в плазме индуцированного ИФН-ү менее 70 пг/мл шансы на наличие у больного саркоидоза выше, чем на наличие туберкулеза в 12,8 раза (95\% ДИ 5,1-32,8).

Диагностическая эфффективность метода при принятом пороговом значении при дифференциальной диагностике ТБ и НВЗЛ равна $66,3 \%$, чувствительность теста составила только 47,7\% при удовлетворительной специфичности - 80\%. Критерий $\chi^{2}$ свидетельствует о достоверности результатов $(p<0,001)$. При концентрации в плазме индуцированного ИФН-ү менее 70 пг/мл шансы на наличие у больного НВЗЛ выше, чем на наличие ТБ, в 3,7 раза (95\% ДИ 1,4-9,6).

Из обследованных пациентов у 48 (80\%) больных туберкулезом концентрация ИФН-ү превысила 70 пг/мл при использовании в качестве антигена-индуктора и PPD и ESAT-6. В то же время данный порог превысила концентрация индуцированного ИФН-ү у $16(23,9 \%)$ пациентов с саркоидозом и у $21(47,7 \%)$ пациента с НВЗЛ.

Концентрация ИФН-ү ниже 70 пг/мл отмечена у 12 (20\%) больных туберкулезом, у 51 (76,1\%) больного

Таблица 1

Статистические показатели концентрации ИФН-ү при индукции PPD

\begin{tabular}{|l|c|c|c|c|c|}
\hline \multicolumn{1}{|c|}{ Заболевание } & $n$ & $M \pm m$ & $95 \%-$ ный ДИ & Min/max & Процентили 25-75\% \\
\hline Туберкулез $^{1}$ & 60 & $302,1 \pm 32,6$ & $236,9-367,4$ & $13,8 / 1069$ & $110-409,5$ \\
\hline Саркоидоз $^{2}$ & 67 & $66,7 \pm 16,8$ & $33,2-100,2$ & $0 / 810$ & $0-68,97$ \\
\hline НВ3Л $^{3}$ & 44 & $198,2 \pm 41,9$ & $113,7-282,7$ & $0 / 1172,4$ & $4,7-268,5$ \\
\hline
\end{tabular}

\begin{tabular}{|c|c|}
\hline U-тест по Манну-Уитни & $p$ \\
\hline 1,2 & 0,001 \\
1,3 & $<0,0005$ \\
2,3 & 0,002 \\
\hline
\end{tabular}

Таблица 2

Статистические показатели концентрации ИФН-ү при индукции ЕSAT-6

\begin{tabular}{|l|c|c|c|c|c|}
\hline \multicolumn{1}{|c|}{ Заболевание } & $n$ & $M \pm m$ & $95 \%$-ный ДИ & Min/max & Процентили 25-75\% \\
\hline Туберкулез $^{1}$ & 60 & $92,8 \pm 16,7$ & $59,3-126,3$ & $0 / 517$ & $17,8-86,2$ \\
\hline Саркоидоз $^{2}$ & 67 & $9,2 \pm 2,98$ & $3,3-15,2$ & $0 / 127,6$ & $0-0$ \\
\hline НВ3Л $^{3}$ & 44 & $95,2 \pm 29,4$ & $35,9-154,4$ & $0 / 910,34$ & $0-69$ \\
\hline
\end{tabular}

\begin{tabular}{|c|c|}
\hline U-тест по Манну-Уитни & $p$ \\
\hline 1,2 & $<0,0005$ \\
1,3 & 0,013 \\
2,3 & $<0,0005$ \\
\hline
\end{tabular}

Диагностические критерии наличия саркоидоза или туберкулеза в зависимости от пороговой величины концентрации ИФН-ү

\begin{tabular}{|l|c|c|c|}
\hline \multirow{2}{*}{ Показатель } & \multicolumn{2}{|c|}{ Пороговые величины индуцированного ИФН-ү на оба антигена } \\
\cline { 2 - 4 } & $<50$ пг/мл & $<70$ пг/мл & $<100$ пг/мл \\
\hline Число больных & 46 & 51 & 56 \\
\hline Отношение шансов (ОR) [95\% ДИ] & $14,2[5,3-39,4]$ & $12,8[5,1-32,8]$ & $18,4[6,9-50,2]$ \\
\hline Чувствительность [95\% ДИ], \% & $68,7[60,6-74,7]$ & $76,1[67,8-82,7]$ & $83,6[75,5-89,7]$ \\
\hline Специфичность [95\% ДИ], \% & $86,7[77,6-93,1]$ & $80[70,7-87,3]$ & $78,3[69,3-85,2]$ \\
\hline Диагностическая эфрфективность, \% & 77,2 & 77,9 & 81,1 \\
\hline Критерий $\mathrm{X}^{2}$ & $p<0,001$ & $p<0,001$ & $p<0,001$ \\
\hline
\end{tabular}


Диагностические критерии наличия НВЗЛ или туберкулеза в зависимости от пороговой величины концентрации ИФН-ү

\begin{tabular}{|l|c|c|c|}
\hline \multirow{2}{*}{\multicolumn{1}{|c|}{ Показатель }} & \multicolumn{2}{|c|}{ Пороговые величины индуцированного ИФН-ү на оба антигена } \\
\cline { 2 - 4 } & $<50$ пг/мл & $<70$ пг/мл & $<100$ пг/мл \\
\hline Число больных & 15 & 21 & 26 \\
\hline Отношение шансов (ОR) [95\% ДИ] & $3,4[1,2-9,9]$ & $3,7[1,4-9,6]$ & $5,2[2,04-13,6]$ \\
\hline Чувствительность [95\% ДИ], \% & $34,1[23,6-42,8]$ & $47,7[36,1-57,9]$ & $59,1[47,2-69,3]$ \\
\hline Специфичность [95\% ДИ], \% & $86,7[79-93]$ & $80[71,5-87,4]$ & $78,3[69,6-85,8]$ \\
\hline Диагностическая эфрфективность, \% & 64,4 & 66,4 & 70,2 \\
\hline Критерий $\mathrm{X}^{2}$ & $p<0,001$ & $p<0,001$ & $p<0,05$ \\
\hline
\end{tabular}

саркоидозом, у 23 (52,3\%) больных НВ3Л. Шансы на наличие туберкулеза легких при концентрации антигениндуцированного ИФН-ү более70 пг/мл выше в 8 раз [95\% ДИ 3,6-18,1], чем на наличие нетуберкулезного заболевания. При этом чувствительность метода составляет 80\% [95\% ДИ 69,6-88,1], а специфичность - 66,7\% [95\% ДИ 61-71]. Диагностическая эффрективность принятого критерия для дифференциальной диагностики туберкулеза и нетуберкулезных заболеваний легких равна 71,4\% (по критерию $\chi^{2} p<0,001$ ).

Из 12 больных туберкулезом с концентрацией индуцированного ИФН-ү ниже 70 пг/мл (как на PPD, так и на ESAT-6) у 7 процесс носил распространенный характер, имелись выраженные признаки интоксикации, распад легочной ткани, бактериовыделение, лейкоцитоз, повышение СОЭ и ү-глобулинов крови. Скорее всего, сниженный выброс ИФН-ү у этих пациентов был связан с перераспределением продуцирующих ИФН-ү Т-лимфоцитов и их преобладанием в зоне воспаления, а не в периферической крови. Кроме того, низкие показатели ИФН-ү могут быть обусловлены истощением иммунной системы у больных с распространенными процессами, массивной гибелью Т-лимфоцитов в ходе защитной реакции организма.

Среди больных саркоидозом только у 2 (3,0\%) пациентов концентрация индуцированного ИФН-ү на оба антигена была выше 70 пг/мл. Первый пациент за 4 года до появления диссеминированного процесса в легочной ткани и увеличения ВГЛУ перенес правосторонний экссудативный плеврит, по поводу которого получал антибиотики широкого спектра действия. Нельзя исключить, что плеврит у данного пациента имел специфический генез, и полученные нами результаты отражают имевшую место сенсибилизацию организма микобактериями туберкулеза. У второй пациентки изменения в легочной ткани и увеличение ВГЛУ выявлены в ходе обследования по поводу кожных изменений, первоначально трактуемых как липоидный некробиоз. В дальнейшем был морфологически верифицирован генерализованный саркоидоз с поражением ВГЛУ, легких, бронхов, кожи. У пациентки отсутствовали изменения гемограммы, биохимических и иммунологических показателей; отрицала пациентка и контакт с больными туберкулезом.

Полученные данные позволяют заключить, что определение антигениндуцированного ИФН-ү позволяет эфффективно дифрференцировать гранулематозные заболевания - саркоидоз и туберкулез, и в меньшей степени - туберкулез и НВЗЛ. Представляется, что данный диагностический метод представляет ценность для клиницистов в сложных дифференциальнодиагностических случаях, особенно при отсутствии однозначного морфологического заключения.

\section{Выводы:}

1. Определение антигенспецифической индукции ИФН-ү позволяет более эффрективно дифференцировать гранулематозные заболевания - саркоидоз и туберкулез, менее эфффективно - туберкулез и НВЗЛ.

2. В качестве оптимального диагностического критерия туберкулеза возможно использовать пороговую величину концентрации ИФН-ү более 70 пг/мл в совокупности при инкубации с антигеном-индуктором PPD и антигеном-индуктором ESAT-6.

3. Продукция ИФН-ү клетками периферической крови после 24-часовой инкубации при индукции ESAT-6 меньше почти в 2 раза, чем при индукции PPD.

4. Отсутствие выброса ИФН-ү клетками периферической крови при индукции ESAT-6 у большинства больных с нетуберкулезными процессами в легких может подтверждать высокую специфичность данного антигена в отличие от PPD, когда возможно влияние предшествующей вакцинации и инфрицирования нетуберкулезными микобактериями.

\section{ЛИТЕРАТУРА}

1. Авдеев, С.Н. Тяжелая внебольничная пневмония / С.Н. Авдеев, А.Г. Чучалин // Рус. мед. журнал. - 2001. - Т. 9, № 5. - С. 177-178.

2. Соловьева, И.П. Гранулематозное воспаление и гранулематозные болезни / И.П. Соловьева // Патология. - М.: Медицина, 2002. - С. 106-120.

3. Шмелев, Е.И. Диффреренциальная диагностика диссеминированных заболеваний легких неопухолевой природы / Е.И. Шмелев // Рус. мед. журнал. - 2001. — Т. 9, № 21 (140). - C. 919-922.

4. Brock, I. Performance of whole blood IFN-gamma test for tuberculosis diagnosis based on PPD or specific antigens ESAT-6 and CFP-10 / I. Brock, M.E. Munk, A. Kok-Jensen, P. Andersen // Int. J. Tuberc. Lung. Dis. — 2001. — Vol. 5. P. $462-467$

5. Ferrand, R.A. Interferon-gamma responses to ESAT-6 in tuberculosis patients early into and after anti-tuberculosis treatment / R.A. Ferrand, G.H. Bothamley, A. Whelan [et al.] // Int. J. Tuberc. Lung. Dis. — 2005. — Vol. 9 (9). - P. 10341039.

6. Mazurek, G.H. Detection of Mycobacterium Tuberculosis Infection by Whole-Blood Interferon-Gamma Release Assay / G.H. Mazurek, P.A. LoBue, C.L. Daley, J. Bernardo [et al.] // Clin. Infect. Dis. - 2003. - Vol. 36 (9). - P. 1207-1208.

7. Mori, T. Specific detection of tuberculosis infection; an interferon- $\gamma$ based assay using new antigens / T. Mori, M. Sakatani, F. Yamagishi, T.T. Takashima [et al.] //Am. J. Respir. Crit. Care Med. — 2004. — Vol. 170 (1). - P. 59-64.

8. Pai, M. New tools and emerging technologies for the diagnosis of tuberculosis: Part I. Latent tuberculosis / M. Pai, S. Kalantri, K. Dheda // Expert. Rev. Mol. Diag. — 2006. — № 6 (3). P. 413-422.

9. Pai, M. Interferon-gamma release assays: what is their role in the diagnosis of active tuberculosis? / M. Pai, D. Menzies // Clin. Infect. Dis. - 2007. — Vol. 44. - P. 74-77. 